\title{
DESIGN OF FRP REINFORCED CONCRETE BEAMS FOR SERVICEABILITY REQUIREMENTS
}

\author{
Cristina Barris $^{1}$, Lluís Torres ${ }^{2}$, Cristina Miàs ${ }^{3}$, Irene Vilanova ${ }^{4}$ \\ Advanced Materials and Analysis for Structural Design, Escola Politècnica Superior, E-17071 Girona, Spain \\ E-mails: ${ }^{1}$ cristina.barris@udg.edu (corresponding author); ${ }^{2} l l u i s . t o r r e s @ u d g . e d u$; \\ ${ }^{3}$ cristina.mias@udg.edu; ${ }^{4}$ irene.vilanova@udg.edu \\ Received 14 Nov. 2011; accepted 29 Feb. 2012
}

\begin{abstract}
Serviceability Limit States (SLS) may govern the design of concrete elements internally reinforced with Fibre Reinforced Polymer (FRP) bars because of the mechanical properties of FRP materials. This paper investigates the design of Fibre Reinforced Polymer reinforced concrete (FRP RC) beams under the SLS of cracking, stresses in materials, and deflections. A formulation to calculate the bending condition at which crack width and stresses in materials requirements are fulfilled is presented based on principles of equilibrium, strain compatibility and linear elastic behaviour of materials. The slenderness limits to comply with the deflection limitation are redefined and a methodology to calculate the optimal height of an FRP RC beam to satisfy all of these serviceability requirements is proposed. This procedure allows optimising the dimensions of an FRP RC beam taking into account the specific characteristics of the element, such as the mechanical properties of materials and the geometric and loading conditions.
\end{abstract}

Keywords: reinforced concrete, FRP bars, flexural behavior, serviceability, deflection, cracking, design.

\section{Introduction}

Corrosion of steel reinforcement in aggressive environments can cause considerable damage in reinforced concrete (RC) structures. In order to avoid such problems, the use of fibre reinforced polymer (FRP) bars for internal longitudinal flexural reinforcement has emerged as an alternative solution. Owing to their non-corrosive nature, the use of FRP bars can reduce maintenance and rehabilitation costs, leading to economic and environmental benefits (ACI 440.1R-06 2006; Hollaway 2010). Moreover, the magnetic neutrality of FRP bars can be exploited in applications where interferences with magnetic fields have to be avoided. In the last two decades, a number of studies have been carried out to investigate the flexural response of Fibre Reinforced Polymer reinforced concrete (FRP RC) elements (Pecce et al. 2000; Matthys, Taerwe 2000; El-Salakawy, Benmokrane 2004; Bischoff 2005; Barris et al. 2012; Soric et al. 2010; Kara, Ashour 2012).

Adequate account of the serviceability behavior and the parameters involved in the post-cracking behavior is of major importance for the design of RC structures (Bischoff 2007; Baena et al. 2011; Gribniak et al. 2010; Kaklauskas et al. 2012). Due to the mechanical properties of FRP materials, the Serviceability Limit States (SLS) may govern the design of FRP RC elements (ISIS Canada 2001; Matthys, Taerwe 2000; Nanni 2003; Saikia et al. 2007; Rafi, Nadjai 2009). At a cross-section level, two requirements limit the SLS: stresses in materials and cracking (Eurocode 2 2004). Stresses in concrete are limited to avoid longitudinal cracking, micro-cracks and high levels of creep. The stress in the FRP reinforcement should also be limited to avoid creep rupture or stress corrosion, which consists in the creep of the material under a constant load after a certain time. In general, cracking is controlled to ensure adequate structural performance as well as sufficient durability of the structure.

The SLS for steel RC elements are usually evaluated at about 60 to $65 \%$ of the nominal moment capacity (Bischoff 2005). Several published studies on SLS for FRP RC elements relate the load at which the SLS shall be evaluated to the ultimate load. Alsayed (1998), Alsayed et al. (2000) and Rafi et al. (2008) assume the service load to be about $35 \%$ of the ultimate load, whereas Bischoff (2005) states that the level of service load drops to about $25 \%$ of the nominal beam capacity for overreinforced GFRP beams. Other investigations and codes of practice limit the tensile strain at the reinforcement to a fix value to control crack width (ISIS Canada 2001; Ghali et al. 2001; Newhook et al. 2002). Pecce et al. (2001), in turn, evaluate the serviceability load as the minimum between the loads corresponding to each of the SLS (namely, deflection, crack width and maximum stress in concrete) and the theoretical ultimate load reduced by factor of 1.5 , finding that in $80 \%$ of the cases, the serviceability load corresponds to the criterion of the concrete limiting stresses.

Deflection requirements are typically assessed by limiting the span-to-depth ratio. Several proposals are 
found in the literature to limit the span-to-depth ratio for both steel and FRP RC members. For example, for FRP RC, Ospina and Gross (2005) give Eq. (1) to calculate $L / h$ :

$$
\frac{L}{h}=\frac{48 d / h}{5 K_{1}}\left[\frac{1}{\left[(1-\zeta) \frac{15 d / h}{57000}+\zeta \frac{\varepsilon_{f}}{1-k}\right]}\right]\left(\frac{\delta}{L}\right)_{\max },
$$

where: $d / h$ is the effective depth-to-total depth ratio; $K_{1}$ is a parameter that accounts for the boundary conditions; $\varepsilon_{f}$ is the reinforcement tensile strain under the service load; $(\delta / L)_{\max }$ is the limiting service deflection-to-span ratio; $\zeta$ and $k$ are dimensionless parameters defined in the following equations:

$$
\begin{gathered}
\zeta=1-\beta\left(\frac{M_{c r}}{M_{s}}\right)^{2}, \\
k=\sqrt{2 n \rho+(n \rho)^{2}}-n \rho .
\end{gathered}
$$

In Eq. (2), $M_{s}$ is the service moment, $M_{c r}$ is the cracking moment, and the coefficients $\beta_{1}$ and $\beta_{2}$ characterize the bond quality of the bars and the influence of load duration or repetition, respectively. In Eq. (3), $n$ is the modular ratio $E_{f} / E_{c}$, where $E_{f}$ and $E_{c}$ are the modulus of elasticity of the FRP reinforcement and the concrete respectively, and $\rho$ is the reinforcement ratio. More recently, Veysey and Bischoff (2011) propose the following equation for the same relationship:

$$
\frac{L}{h}=\sqrt[3]{\frac{8\left(\phi / \alpha_{D+L}\right) R_{n}(d / h)^{3}}{(w / L)(d / b)\left(M_{a} / M_{0}\right)}},
$$

in which $\phi$ is the strength reduction factor, $\alpha_{D+L}$ is the averaged load factor, $M_{0}$ is the total static moment and $R_{n}$ is the nominal moment capacity $M_{n}$ divided by $b d^{2}$. As observed, both approaches need to be evaluated at a certain moment ratio.

This paper presents a formulation to calculate the bending condition at which crack width and stresses in materials requirements are fulfilled. The presented equations are based on principles of equilibrium and strain compatibility, and linear elastic behaviour of materials. The formulation of the Italian code for FRP RC (CNRDT-203 2006) and Eurocode 2 (2002) is considered for the crack width calculation. Comparisons between both limitations are presented in terms of the service moment related to the cracking moment and the corresponding tensile stress at the reinforcement. Deflection limitation is studied and the slenderness limits are redefined at the load level that satisfies both the maximum crack width and the stresses in materials limitations. Finally, a methodology is proposed for the design under the serviceability conditions of FRP RC. This methodology allows optimizing the overall depth of the element with respect to those usually adopted in practice, since it takes account of the specific characteristics of the RC element.

\section{Discussion on the serviceability limitations and proposed formulation}

Nowadays there is no evidence for establishing the principles behind the verification of SLS of FRP RC elements different to those already considered in design codes for steel RC elements. Nevertheless, the different properties of FRP and steel reinforcements might justify different limits in the case of the short and long-term behaviour (ACI 440.1R-06 2006). In this section, a discussion of the serviceability limitations for the case of FRP RC beams is made and a formulation to assess the serviceability requirements is suggested.

\subsection{Stresses in materials}

When FRPs are used as internal reinforcement, the strength to stiffness ratio is an order of magnitude greater than that of concrete and, hence, the neutral axis depth for the balanced section is very close to the compressive end. As a result, higher compressive strains than in a steel RC section are expected to develop in the concrete for the same beam depth. Consequently, the maximum concrete strain/stress at the service load should be considered carefully so as to avoid any undesirable effects due to the occurrence of longitudinal cracks, micro-cracks, inelastic deformations and creep. Moreover, the stress at the FRP reinforcement shall be limited in order to avoid creep rupture and stress corrosion, although this limitation highly depends on the type of FRP reinforcement and environmental conditions.

\subsubsection{Stresses in concrete}

Although specific limits on concrete compression stresses under service conditions are not prescribed explicitly in all of the existing design provisions, the concrete stresses are generally assumed to be within the linear range. While ACI 440.1R-06 (2006) adopts this latter approach, a limiting value of $0.45 f_{c}^{\prime}$ is explicitly recommended in ACI 440.2R-08 (2008) for concrete elements strengthened with FRPs.

Eurocode 2 (2004) imposes a maximum stress in concrete of $0.60 f_{c k}$ under a characteristic combination of loads to avoid the appearance of longitudinal cracks, which could affect durability. A more restrictive limit of $0.45 f_{c k}$ is recommended when considering quasipermanent load conditions to enable the use of a simplified linear model for creep. The most restrictive limitation between them depends on the permanent-to-variable ratio of loading and on the use of the structure. For a typical permanent-to-total load ratio of $60-75 \%$, the stress limitation under the quasi-permanent combination of loads results more restrictive than that for the characteristic combination.

Consequently, in this study, the limitation of the concrete stress to $0.45 f_{c k}$ and its effects are analysed. As a result, the ratio $M_{s} / M_{c r}$ between the service moment (referred to the quasi-permanent load combination) and the cracking moment that satisfies this stress limitation is presented. The study is developed for FRP RC cracked rectangular sections. 
Assuming elastic behaviour and that the Bernoulli hypothesis is satisfied, the curvature of a cracked section $\kappa_{c r}$ is:

$$
\kappa_{c r}=\frac{\varepsilon_{c}}{x},
$$

where $\varepsilon_{c}$ is the maximum concrete strain and $x$ is the distance from the top surface to the neutral axis (Fig. 1).

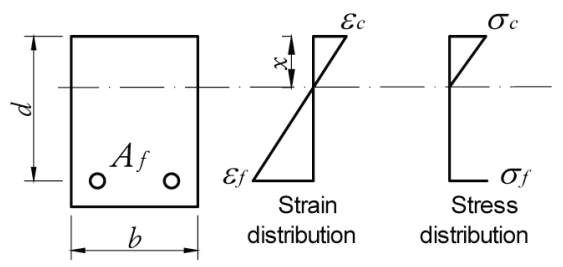

Fig. 1. Strain and stress distribution at a cracked section at the serviceability conditions

When $\sigma_{c}$ is $0.45 f_{c k}$, Eq. (5) can be rewritten as:

$$
\kappa_{c r}=0.45 \frac{f_{c k}}{E_{c}} \frac{1 / d}{x / d},
$$

where $x / d$ is a dimensionless parameter that, in the absence of compression reinforcement, only depends on the modular ratio $n=E_{f} / E_{c}$ and the reinforcement ratio $\rho$ :

$$
x / d=n \rho \cdot\left(-1+\sqrt{1+\frac{2}{n \rho}}\right) .
$$

Alternatively, the curvature defined in Eq. (5) can be written as the flexural moment divided by the stiffness of the cracked section as:

$$
\kappa_{c r}=\frac{M}{E_{c} I_{c r}},
$$

in which $M$ is the applied moment and $I_{c r}$ is the moment of inertia of the cracked section. The dimensionless relationship between the applied moment $M$ and the cracking moment $M_{c r}$ is then rewritten as:

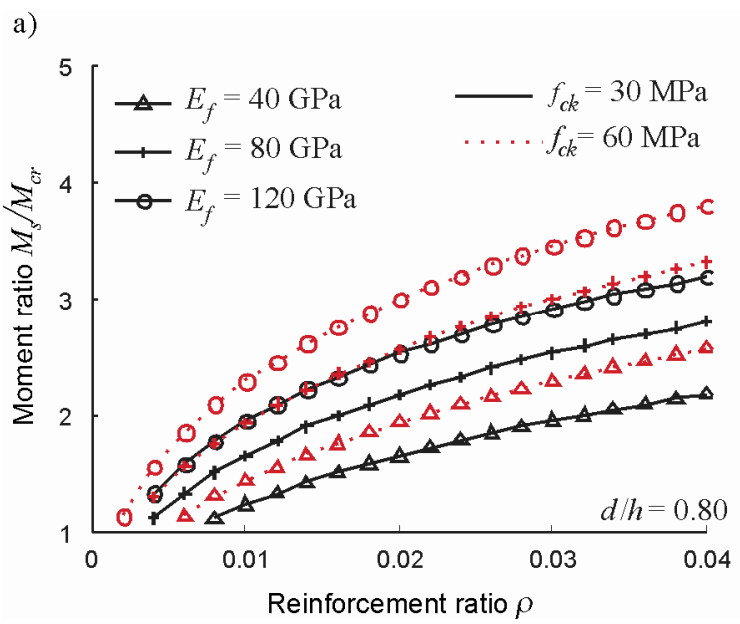

$$
\frac{M}{M_{c r}}=\kappa_{c r} \frac{E_{c}}{f_{c t}} \frac{I_{c r}}{W}
$$

being $f_{c t}$ the concrete tensile strength and $W$ the section modulus of the uncracked section. Considering the applied moment as the service moment $M_{s}$, and substituting Eq. (6) into Eq. (9), the dimensionless service moment ratio $M_{s} / M_{c r}$ is:

$$
\frac{M_{s}}{M_{c r}}=\frac{0.45 f_{c k}}{f_{c t}} \cdot \frac{A}{(x / d)},
$$

where $A$ is a dimensionless parameter defined as:

$$
A=(d / h)^{2}\left(2(x / d)^{3}+6 n \rho \cdot(1-x / d)^{2}\right) .
$$

The dimensionless service moment ratio $M_{s} / M_{c r}$ is only governed by the concrete compressive and tensile strengths, $n \rho$ (modular ratio times reinforcement ratio) and the effective depth to overall height ratio $d / h$.

Fig. 2 depicts $M_{s} / M_{c r}$ depending on the reinforcement ratio $\rho$, for different concrete mechanical properties $\left(f_{c k}, E_{c}\right)$, rebar modulus of elasticity $E_{f}$ and $d / h$ ratios. Fig. 2a represents a typical case where $d / h$ is 0.8 and Fig. $2 \mathrm{~b}$ a case where $f_{c k}$ is $45 \mathrm{MPa}$ and $E_{f}$ is $80 \mathrm{GPa}$. In this study, the tensile strength $f_{c t}$ and the modulus of elasticity $E_{c}$ are calculated according to Eurocode 2 (2004) formulation for a given concrete compressive strength $f_{c k}$. It is observed that the ratio $M_{s} / M_{c r}$ increases with $\rho, f_{c k}, E_{f}$ and $d / h$ and, for the selected reinforcement ratios, its values range between 1 and 4 .

Fig. 2 shows somehow restrictive results of the flexural moment (if compared to flexural capacity). For example, after Fig. $2 \mathrm{~b}$, for $\rho=0.02, f_{c k}=45 \mathrm{MPa}, E_{f}=$ $80 \mathrm{GPa}$ and $d / h=0.80$, the maximum flexural moment that complies with this condition is of 2.4 times the cracking moment. For the correct interpretation of this value, two assumptions shall be taken into account. First, this limitation corresponds to the quasi-permanent loading condition, which is only part of the characteristic service load. If only a portion of the service load is sustained, then the full service load corresponding to limiting

b)

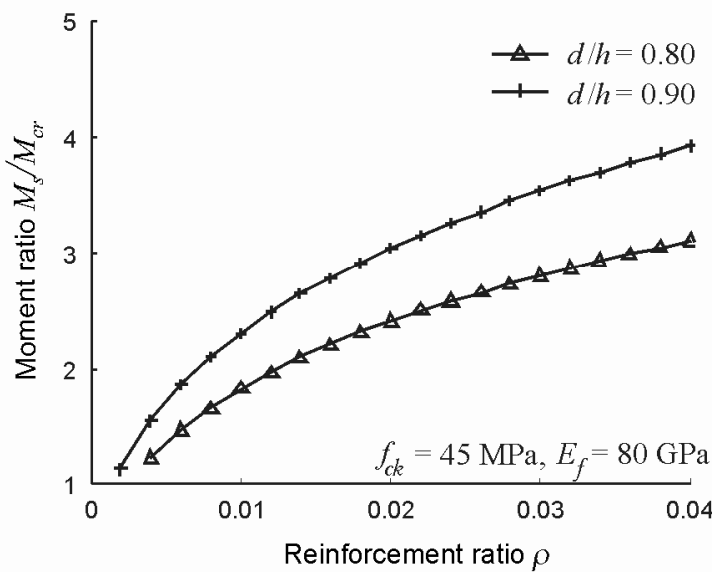

Fig. 2. $M_{s} / M_{c r}$ that complies with $\sigma_{c} \leq 0.45 f_{c k}$ 
the concrete stress to $0.45 f_{c k}$ would be higher. Second, the concrete stress is usually limited to assume linear creep and to avoid longitudinal cracks that may lead to a reduction in durability. For concrete sections reinforced with FRPs, where durability may not be a concern, this limitation could be relaxed depending on the requirements of the structure and the accuracy on the estimation of creep effects.

On the other hand, the tensile strain developed in the reinforcement at the cracked section $\varepsilon_{f}$ could also be a useful parameter of design when considering the SLS (Newhook et al. 2002). This parameter can be calculated considering the hypothesis that the concrete stress may be less than $0.45 f_{c k}$ and fully cracked section:

$$
\varepsilon_{f}=\frac{0.45 f_{c k}}{E_{c}} \cdot \frac{1-x / d}{x / d} .
$$

Fig. 3 represents the maximum value of $\varepsilon_{f}$ that fulfils the condition $\sigma_{c} \leq 0.45 f_{c k}$ depending on $\rho$, for different concrete mechanical characteristics $\left(f_{c k}, E_{c}\right)$ and rebar modulus of elasticity $E_{f}$. The allowable value of $\varepsilon_{f}$ decreases with $\rho$ and $E_{f}$, whilst increases with $f_{c k}$. For low values of $\rho, \varepsilon_{f}$ increases up to $2000-6000 \mu \varepsilon$ and it descends to $600-2500 \mu \varepsilon$ as $\rho$ increases.

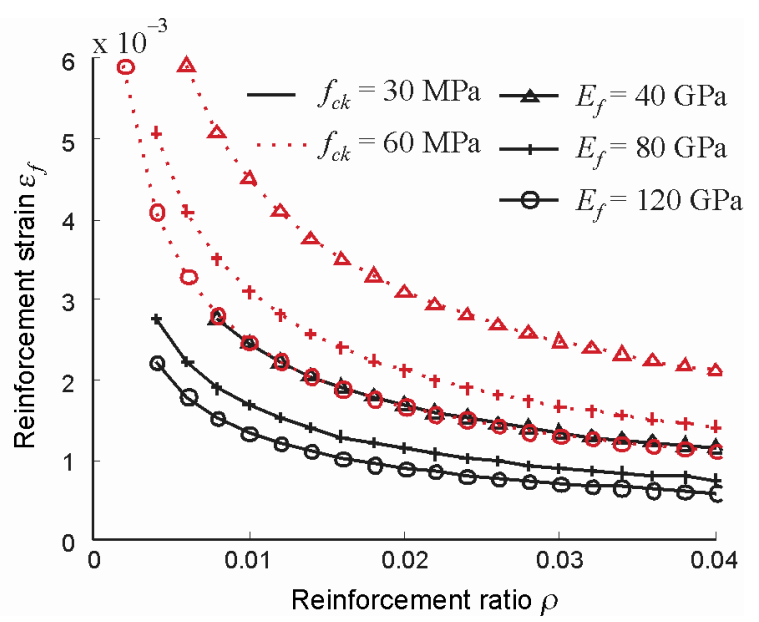

Fig. 3. $\varepsilon_{f}$ that complies with $\sigma_{c} \leq 0.45 f_{c k}$

\subsubsection{Stresses in the FRP reinforcement}

The stress in the FRP reinforcement should be limited to avoid creep rupture or stress corrosion. Stress corrosion related problems are only significant, however, when using glass fibre reinforced composites. Different strength reduction factors are proposed in existing design documents to determine the appropriate limits depending on the different types of FRP reinforcement (ISIS Canada 2001; ACI 440.1R-06 2006). On the other hand, FRP bars present high variability in their composition and mechanical properties making it difficult to establish a general limitation of stresses in FRP reinforcements. Significant differences are found in design codes to limit the stress in the FRP reinforcement in order to avoid creep rupture or stress corrosion (Huang, Aboutaha 2010). Further studies would be needed to arrive to a more generalised conclusion, since this limitation highly depends on the FRP rebar properties (which are improving continuously owing to the rapid advances in manufacturing technology), the environmental conditions and the loading period. For these reasons, this limitation is excluded from this study.

\subsection{Maximum crack width}

In general, cracking in $\mathrm{RC}$ elements is limited to ensure adequate structural performance as well as sufficient durability of the structure (Eurocode 2 2004). When FRPs are used as internal reinforcement, greater crack widths are likely to occur in comparison to equivalent conventional steel reinforced sections (similar reinforcement ratio); nevertheless, as superior durability is expected from FRP RC elements, crack width limits could be relaxed in those cases where aesthetic appearance is not of primary concern. On the basis of the above considerations, all the aspects of design that have a direct effect on the overall cracking behaviour of FRP RC elements, such as the minimum reinforcement area, maximum bar diameter or bar spacing, should be re-assessed to account for the mechanical and physical properties of FRPs, which are responsible of their unique bond behaviour.

Usually, crack width is limited by establishing an upper bound value such as $0.5 \mathrm{~mm}$ for interior exposures and $0.7 \mathrm{~mm}$ for exterior exposures (ACI 440.1R-06 2006). Other approaches, however, limit the value of the tensile stress at the reinforcement to control the crack width. In the design of steel RC, the value of steel stress $f_{s}$ at service loads is typically taken as $60 \% f_{y}$ (being $f_{y}$ the reinforcement yielding strength) in crack control calculations, and the corresponding steel strain for this stress is $1200 \mu \varepsilon$. When GFRP bars are used as internal reinforcement an upper limit on bar strain equal to $2000 \mu \varepsilon$ is used to limit crack widths (ISIS Canada 2001; Newhook et al. 2002).

In this section, a formulation to calculate the maximum dimensionless service moment $M_{s} / M_{c r}$ considering a crack width limitation of $0.5 \mathrm{~mm}$ (ACI 440.1R-06 2006) is developed. The value of the tensile reinforcement strain corresponding to $M_{s} / M_{c r}$ is also provided.

First, the maximum crack width at the service moment is evaluated following the formulation of Eurocode 2 (2002), used as a basis for CNR-DT-203 (2006). Hence, according to Eurocode 2:

$$
w_{k}=\beta \cdot w=\beta \cdot s_{r m} \cdot \varepsilon_{f m},
$$

where: $w_{k}$ is the design crack width; $w$ is the mean crack width; $s_{r m}$ is the average final crack spacing; $\varepsilon_{f m}$ is the allowed mean strain under the relevant combination of loads; and $\beta$ is a coefficient relating the average crack width to the design value. In this study, the value of $\beta$ is taken as 1.7 , corresponding to a case of a load induced cracking. The mean crack width $w$ is therefore defined as the design crack width $w_{k}$ divided by the coefficient $\beta$. The mean strain at the reinforcement $\varepsilon_{f m}$ may be calculated from the relation: 


$$
\varepsilon_{f m}=\varepsilon_{f}\left(1-\beta_{1} \beta_{2}\left(\frac{M_{c r}}{M_{s}}\right)^{2}\right),
$$

in which $\varepsilon_{f}$ is the strain in the tension reinforcement calculated on the basis of a cracked section; $\beta_{1}$ is 1.0 for high bond and 0.5 for plain bars; and $\beta_{2}$ is 1.0 for single, short-term loading and 0.5 for sustained loads. The average final crack spacing for members subjected dominantly to flexure or tension can be calculated from the equation:

$$
s_{r m}=50+0.25 \cdot k_{1} \cdot k_{2} \frac{\phi}{\rho_{\text {eff }}},
$$

where: $\phi$ is the bar size in $\mathrm{mm} ; k_{1}$ a bond coefficient, being 0.8 for high bond bars and 1.6 for plain bars; $k_{2}$ is 0.5 for bending and 1.0 for pure tension; $\rho_{\text {eff }}$ is the effective reinforcement ratio. If the effective height of concrete surrounding the reinforcement is taken as 2.5 times the distance from the tension face of the section to the centroid of the reinforcement:

$$
\rho_{\text {eff }}=\frac{A_{f}}{A_{c, e f f}}=\frac{A_{f}}{b \cdot 2.5(h-d)}=\frac{\rho}{2.5\left((d / h)^{-1}-1\right)} .
$$

Considering $k_{2}=0.5$ (CNR-DT-203 2006), the average crack spacing $s_{r m}$ can be written as:

$$
s_{r m}=50+0.3125 \cdot k_{1} \frac{\phi}{\rho}\left((d / h)^{-1}-1\right) .
$$

The service moment $M_{s}$ is derived from the curvature of the cracked section:

$$
\kappa_{c r}=\frac{M_{s}}{E_{c} I_{c r}}=\frac{\varepsilon_{f}}{d-x} .
$$

Rearranging terms in Eq. (18), the following $M_{s} / M_{c r}$ ratio is obtained:

$$
\frac{M_{s}}{M_{c r}}=\varepsilon_{f} \frac{E_{c}}{f_{c t}} \cdot \frac{A}{(1-x / d)},
$$

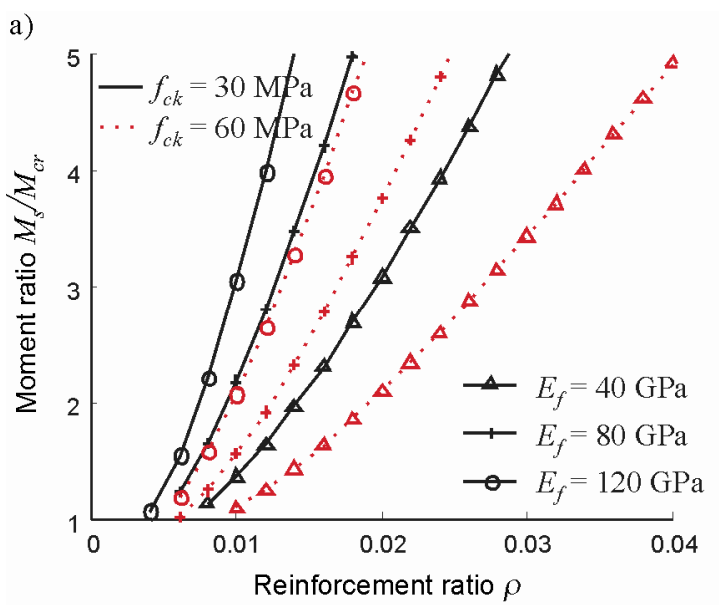

where $A$ is the dimensionless parameter defined in Eq. (11). From Eqs. (13) and (19), the dimensionless moment ratio $M_{s} / M_{c r}$ and the corresponding tensile strain at the reinforcement $\varepsilon_{f}$ are:

$\frac{M_{s}}{M_{c r}}=\frac{w / s_{r m}+\sqrt{\left(w / s_{r m}\right)^{2}+4 \beta_{1} \beta_{2}\left(f_{c t} / E_{c}\right)^{2}\left(\frac{1-x / d}{A}\right)^{2}}}{2 f_{c t}(1-x / d) /\left(E_{c} \cdot A\right)}$,

$\varepsilon_{f}=\frac{w / s_{r m}+\sqrt{\left(w / s_{r m}\right)^{2}+4 \beta_{1} \beta_{2}\left(f_{c t} / E_{c}\right)^{2}\left(\frac{1-x / d}{A}\right)^{2}}}{2}$.

Eqs (20) and (21) allow calculating $M_{s} / M_{c r}$ and $\varepsilon_{f}$ once the maximum permitted crack width is set, depending on $d / h, \rho, E_{f}, \phi$, the bond properties between the rebar and the concrete, the duration of the load, and the concrete mechanical properties $E_{c}$ and $f_{c t}$. The influence of these parameters on $M_{s} / M_{c r}$ and $\varepsilon_{f}$ is represented in Figs 4 and 5, respectively, for a maximum crack width $w_{k}$ of $0.5 \mathrm{~mm}$, assuming high bond properties and long-term loading.

From Fig. 4 it is noted that the ratio $M_{s} / M_{c r}$ increases with the studied parameters $\rho, E_{f}$ and $d / h$, while it decreases with $\phi$ and $f_{c k}$. In Fig. 5 it is observed that the reinforcement tensile strain $\varepsilon_{f}$ increases with $d / h$ and $f_{c k}$, and that it decreases with $\phi$, whilst it increases when $E_{f}$ decreases. The influence of $E_{f}$ and $f_{c k}$ significantly reduces as $\rho$ increases. This trend may be justified by the effect of the crack spacing parameter, which is independent of the load and shows an exponential decay relationship with the reinforcement ratio. For high reinforcement ratios, $s_{r m}$ is relatively small, allowing higher values of $\varepsilon_{f}$.

In the depicted case of $f_{c k}=45 \mathrm{MPa}, E_{f}=80 \mathrm{GPa}$, high bond condition and long-term loading, $\varepsilon_{f}$ can be generally higher than $2000 \mu \varepsilon$ to obtain maximum values of crack width of $0.5 \mathrm{~mm}$. Only for the combination of $\phi=32 \mathrm{~mm}$ and $d / h=0.80, \varepsilon_{f}$ shall be lower than $2000 \mu \varepsilon$ to attain $w_{k} \leq 0.5 \mathrm{~mm}$. Hence, in those cases where high

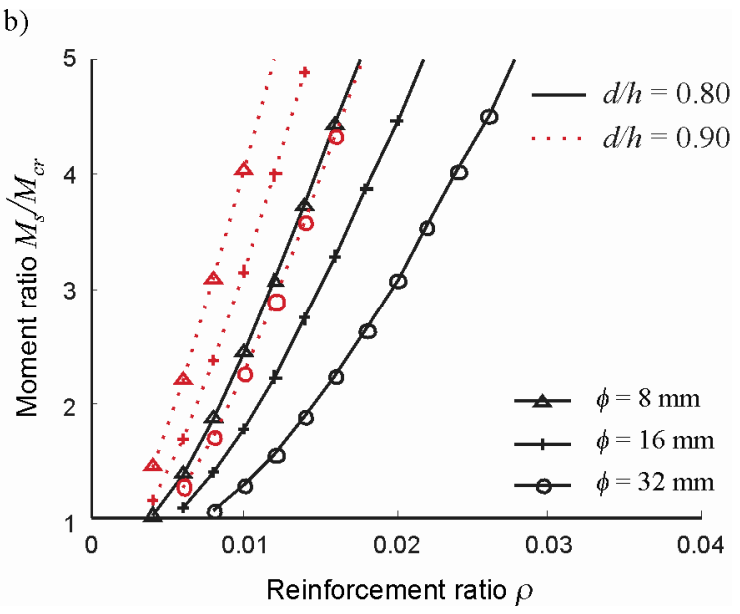

Fig. 4. $M_{s} / M_{c r}$ versus $\rho$. Assumptions: $w_{k}=0.5 \mathrm{~mm}$, high bond, long-term loading; (a) $\phi=16 \mathrm{~mm}, d / h=0.80$; (b) $f_{c k}=45 \mathrm{MPa}, E_{f}=80 \mathrm{GPa}$ 

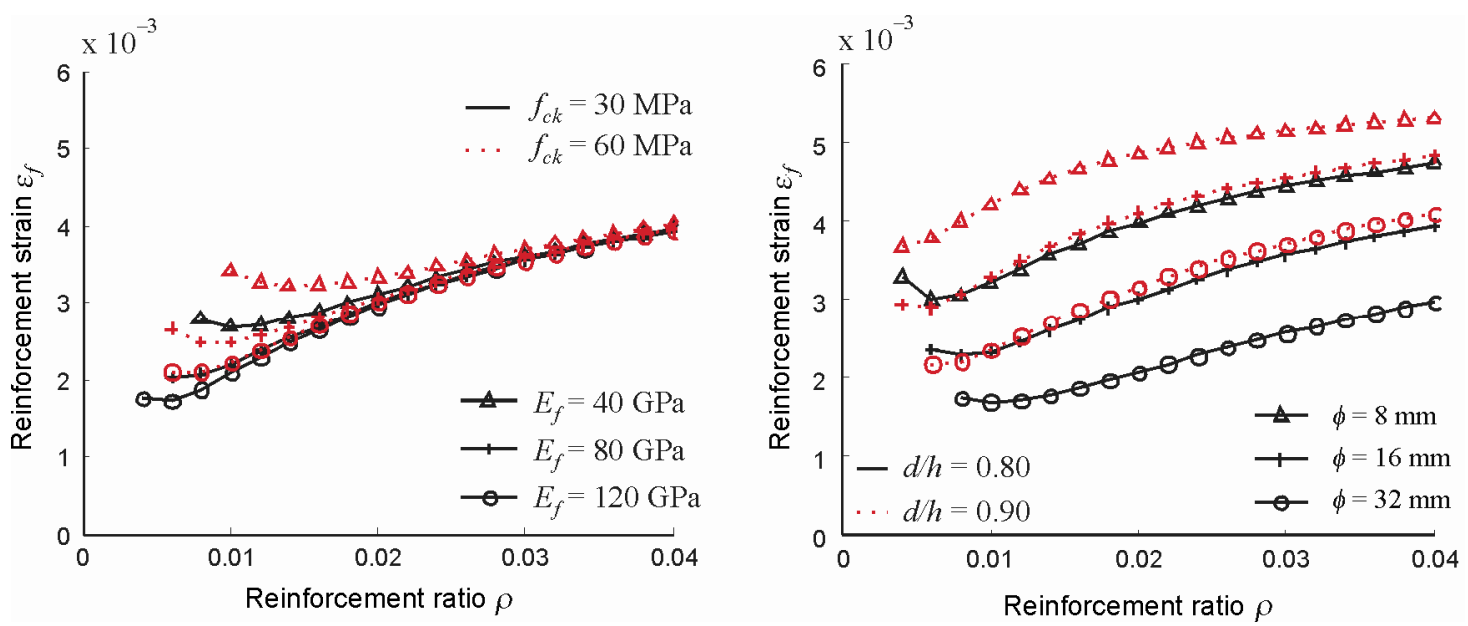

Fig. 5. $\varepsilon_{f}$ versus $\rho$. Assumptions: $w_{k}=0.5 \mathrm{~mm}$, high bond, long-term loading;

(a) $\phi=16 \mathrm{~mm}, d / h=0.80$; (b) $f_{c k}=45 \mathrm{MPa}, E_{f}=80 \mathrm{GPa}$
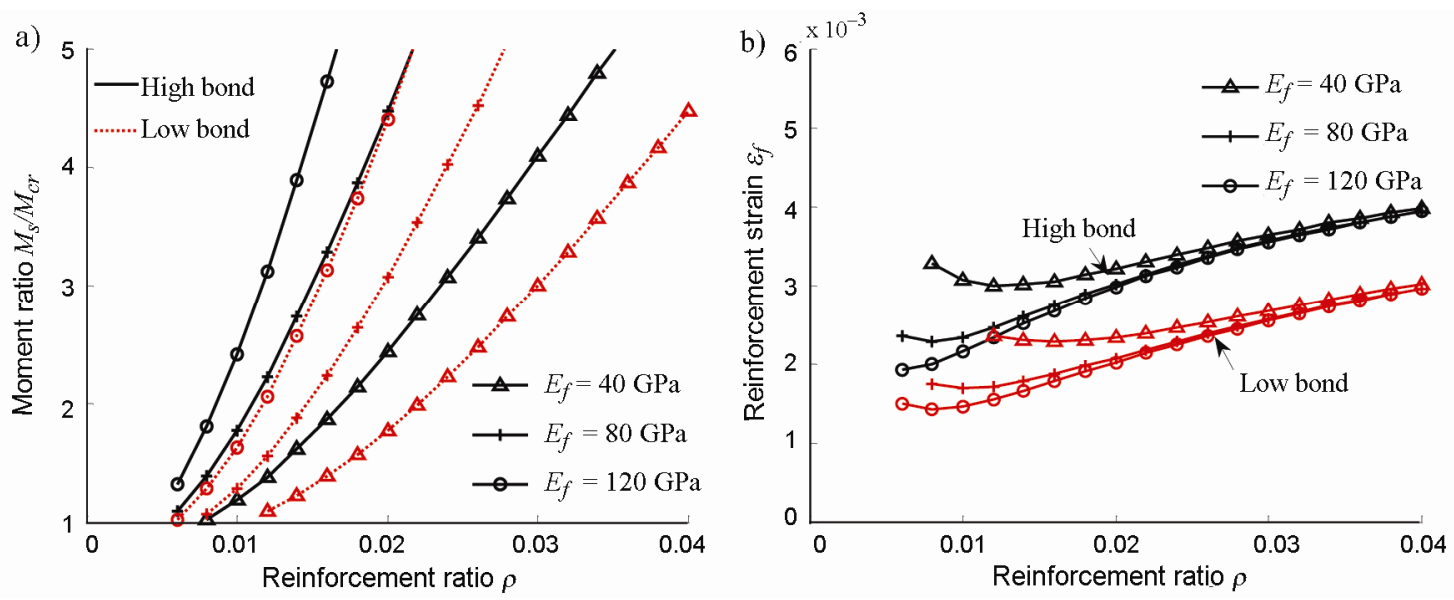

Fig. 6. $M_{s} / M_{c r}$ and $\varepsilon_{f}$ for different bond characteristics. Assumptions: $w_{k}=0.5 \mathrm{~mm}$, long-term loading; $f_{c k}=45 \mathrm{MPa} ; \phi=16 \mathrm{~mm} ; d / h=0.80$

bond is provided, limiting the tensile strain to $2000 \mu \varepsilon$ to control the crack width (ISIS Canada 2001; Newhook et al. 2002) can lead to an oversizing of the cross-section.

The impact of the bond coefficient in the curves is depicted in Fig. 6. As expected, better bond allows higher $M_{s} / M_{c r}$ ratios and higher values of $\varepsilon_{f}$. For the case of low bond between the concrete and the rebar, the maximum value of $\varepsilon_{f}$ can result lower than $2000 \mu \varepsilon$ if $E_{f} \geq 80 \mathrm{GPa}$ and $\rho<0.02$, where the maximum value of $\varepsilon_{f}$ ranges between 1200 and $2100 \mu \varepsilon$.

\subsection{Serviceability requirements at a cross-section level: comparison between stresses in concrete and maximum crack width limitations}

The allowable service moment that satisfies the serviceability conditions at a cross-section level is found from comparison between the limitation of stresses in materials and from the maximum crack width limitation. The minimum value between these two limitations corresponds to the loading condition that fulfils both serviceability requirements. At the same time, this minimum moment gives the flexural condition that allows calculating the maximum tensile strain at the reinforcement. Both requirements refer to the quasi-permanent loading condition.

\subsubsection{Maximum service moment related to the cracking moment}

From comparison between Fig. $2\left(M_{s} / M_{c r}\right.$ for the stresses in materials limitation) and Fig. $4\left(M_{s} / M_{c r}\right.$ for the maximum crack width limitation), a value for the maximum $M_{s} / M_{c r}$ ratio that fulfils both serviceability requirements can be obtained, assuming the minimum between them, which is depicted in Fig. 7.

The concrete stress limitation governs the design of FRP RC sections with high reinforcement ratios, whilst for lightly reinforced sections, the design would be governed by the crack width limitation. Furthermore, low bond between the concrete and the rebar results in a shift to the right hand side of the graph of the maximum $M_{s} / M_{c r}$ ratio from crack width limitation, indicating that if low bond is reported, higher reinforcement ratios are needed for the same mechanical and loading characteristics. 


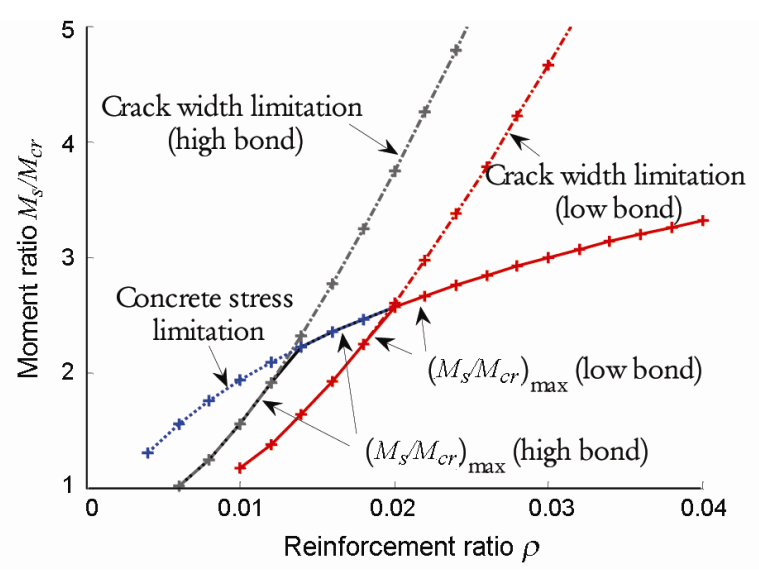

Fig. 7. Maximum $M_{s} / M_{c r}$ that complies with stresses in materials and maximum crack width limitations. Assumptions: $\sigma_{c}=0.45 \mathrm{f}_{c k} ; w_{k}=0.5 \mathrm{~mm} ; \phi=16 \mathrm{~mm} ; d / h=0.80 ; f_{c k}=60 \mathrm{MPa}$; $E_{f}=80 \mathrm{GPa}$

\subsubsection{Maximum service moment related to the ultimate moment}

Assuming a typical concrete crushing failure of the section, the service moment related to the ultimate moment $M_{s} / M_{u}$ can be found from the $M_{s} / M_{c r}$ relationship:

$$
\frac{M_{s}}{M_{u}}=\left(\frac{M_{s}}{M_{c r}}\right) \cdot\left(\frac{M_{c r}}{M_{u}}\right) \text {. }
$$

The ultimate moment $M_{u}$ is deduced from compatibility and equilibrium of forces considering the equivalent stress block of concrete under compression (Eurocode 2 2004; ACI 440.1R-06 2006):

$$
\begin{gathered}
\frac{x}{d}=\frac{\varepsilon_{c u}}{\varepsilon_{c u}+\varepsilon_{f}}, \\
A_{f} E_{f} \varepsilon_{f}=\lambda \cdot x \cdot f_{c d} \cdot b, \\
M_{u}=\lambda \cdot x \cdot f_{c d} \cdot b \cdot(d-0.5 \lambda \cdot x),
\end{gathered}
$$

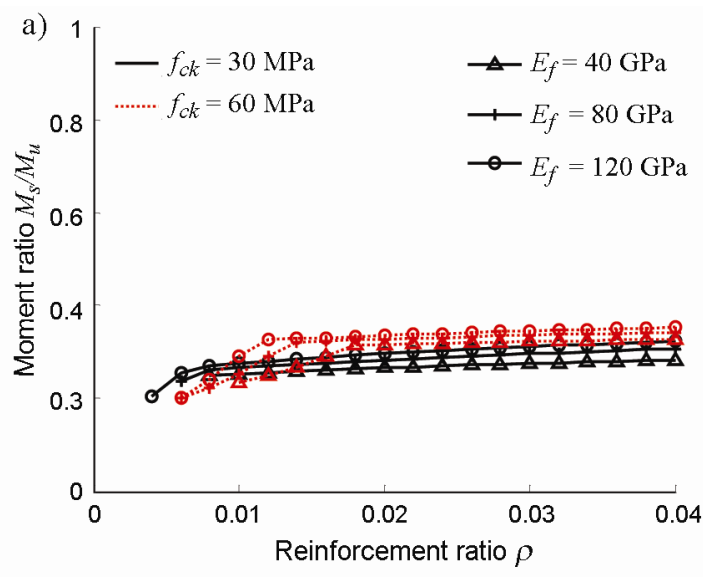

where $\lambda$ is the parameter for the depth of the equivalent concrete stress block. Assuming a concrete crushing mode, according to Eurocode 2 (2004), $\varepsilon_{c u}=0.35 \%$, $\lambda=0.8$, the neutral axis depth can be calculated as:

$$
x=\frac{-A_{f} \cdot E_{f}+\sqrt{\left(A_{f} \cdot E_{f}\right)^{2}+914.29 \cdot f_{c d} \cdot b \cdot A_{f} \cdot E_{f} \cdot d}}{457.14 \cdot f_{c d} \cdot b},
$$

allowing obtaining $M_{u}$ from Eq. (25). Fig. 8 represents the maximum service to ultimate moment ratio $M_{s} / M_{u}$. For the studied range of values, the flexural moment that satisfies both serviceability limitations varies from $20 \%$ to $38 \% M_{u}$. Bischoff (2005) and Ospina and Gross (2005) suggested a reference value for the service moment of FRP RC of $0.35 M_{u}$; this value lies within the minimum and maximum of the interval obtained in the present study.

\subsection{Deflection limitation and slenderness limits}

The deformation of a RC member or structure is usually limited so as not to be such that it adversely affects its proper functioning or appearance. Appropriate limiting values of deflection taking into account the nature of the structure, of the finishes, partitions and fixings and upon the function of the structure should be established. Eurocode 2, for example, limits the sag of a beam, slab or cantilever subjected to quasi-permanent loads to span/250 not to impair the appearance and general utility of the structure.

The low stiffness of FRP reinforcement always results in the larger deflections of FRP RC elements in comparison to equivalent concrete elements reinforced with conventional steel reinforcement. As a result, required amounts of flexural reinforcement and initial element sizing, in terms of recommended span to depth ratios, have to be re-examined in the light of the above considerations.

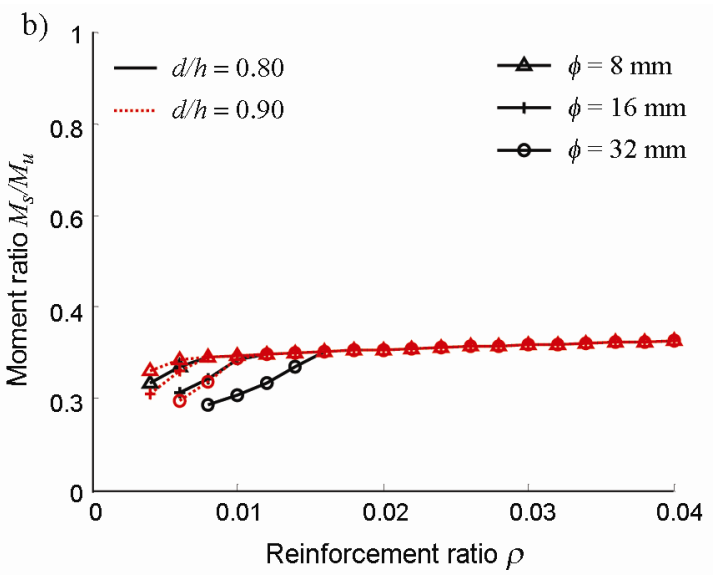

Fig. 8. Maximum $M_{s} / M_{u}$ that complies with stresses in materials and maximum crack width limitations. Assumptions: $\sigma_{c}=0.45 f_{c k}, w_{k}=0.5 \mathrm{~mm}$ and high bond; (a) $\phi=16 \mathrm{~mm}, d / h=0.80$; (b) $f_{c k}=45 \mathrm{MPa}, E_{f}=80 \mathrm{Gpa}$ 
Codes of practice usually propose a slenderness limitation to avoid calculation of deflections. In this section, a general formulation to calculate the slenderness limitation for FRP RC elements is suggested. This formulation is based on the instantaneous deflection proposed in Eurocode 2 (2004). For the sake of simplicity, a procedure based on a multiplicative coefficient for FRP RC taken from ACI 440 (2006) is used for the calculation of longterm deflections.

\subsubsection{Instantaneous deflection}

The flexural deflection of a RC beam can be computed, according to Eurocode 2 (2004), from interpolation of deflections as:

$$
\begin{aligned}
& \delta=\delta_{2} \zeta+\delta_{1}(1-\zeta), \\
& \zeta=1-\beta_{1} \beta_{2}\left(\frac{\sigma_{f r}}{\sigma_{f}}\right)^{2},
\end{aligned}
$$

where: $\delta_{1}$ is the deflection under the uncracked condition; $\delta_{2}$ is the deflection under the fully cracked condition; $\zeta$ is a distribution coefficient defined in Eq. (28), being $\beta_{1}$ and $\beta_{2}$ the factors described in Eq. (14) and the ratio $\sigma_{f r} / \sigma_{f}$ is equivalent to $M_{c r} / M_{s}$ for flexure.

The generalized elastic equation for midspan deflection can be expressed depending on the curvature of the midspan section $\kappa_{i}$ and the overall length as follows:

$$
\delta_{i}=K_{1} K_{2} \kappa_{i} L^{2},
$$

where $K_{1}$ is the coefficient related to the loading condition, being $5 / 48$ for uniform load or 23/216 for four-point loading with loads applied at $L / 3$ and $K_{2}$ is the beam deflection coefficient depending on the boundary and loading conditions:

$$
K_{2}=1.2-0.2 \frac{M_{0}}{M_{m}},
$$

where $M_{0}$ is the total static moment and $M_{m}$ refers to the moment at midspan. For uniform loading, $K_{2}=1$ for simply supported spans, $K_{2}=0.8$ for fixed-hinged beams and $K_{2}=0.6$ for fixed-fixed beams.

The uncracked and cracked curvatures of the midspan section can be calculated by Eqs (31) and (8), respectively:

$$
\kappa_{u n c}=\frac{M_{s}}{E_{c} I_{g}}=\frac{M_{s}}{M_{c r}} \frac{f_{c t}}{E_{c}} \frac{2}{h} .
$$

Substituting Eqs (31) and (8) into Eqs (27) and (29), the following expression is obtained:

$$
\begin{gathered}
\frac{\delta}{L}=\frac{L}{h} K_{1} K_{2} . \\
\left(2 \frac{f_{c t}}{E_{c}} \beta_{1} \beta_{2}\left(\frac{M_{c r}}{M_{s}}\right)+\frac{\varepsilon_{f}}{d / h(1-x / d)}\left(1-\beta_{1} \beta_{2}\left(\frac{M_{c r}}{M_{s}}\right)^{2}\right)\right) .
\end{gathered}
$$

If the ratio $\delta / L$ is limited to $1 / 250$, the following equation is found for the $L / d$ ratio:

$$
\begin{gathered}
\frac{L}{d} \leq \frac{1}{250 K_{1} K_{2}}(d / h)^{-1} . \\
\left(2 \frac{f_{c t}}{E_{c}} \beta_{1} \beta_{2}\left(\frac{M_{s}}{M_{c r}}\right)^{-1}+\frac{\varepsilon_{f}}{d / h(1-x / d)}\left(1-\beta_{1} \beta_{2}\left(\frac{M_{s}}{M_{c r}}\right)^{-2}\right)\right)^{-1} .
\end{gathered}
$$

The resulting $L / d$ ratio depends on $d / h, \rho, E_{f}$, the bond properties between the rebar and the concrete, the duration of the load, the concrete mechanical properties $E_{c}$ and $f_{c t}$ and the dimensionless service moment related to the cracking moment $M_{s} / M_{c r}$, and its corresponding tensile strain $\varepsilon_{f}$ at a cracked section.

\subsubsection{Long-term deflection}

The long-term deflection can be computed following different procedures with different degrees of complexity. One of the most simple and wide-spread procedures for the calculation of deflections for RC elements, consists of applying multiplicative coefficients to the instantaneous deflection. For the case of FRP RC, ACI 440.1R-06 (2006) proposes a reduction coefficient of 0.6 , to be applied on the multiplicative coefficient used for steel RC elements.

In this study, FRP RC elements are supposed to support non structural elements not likely to be damaged by large deflections. For this case ACI limits the deflection to $L / 240$, whilst Eurocode 2 (2004) states that other limits than $L / 500$ may be considered, depending on the sensitivity of adjacent parts. In the following, for simplicity and comparative reasons, the long-term deflection $\delta_{L T}$ after construction of adjacent parts under the quasipermanent loading condition is limited to $L / 250$. However, the present formulation allows changing this limit if different cases are to be considered.

The long term deflection is computed as:

$$
\delta_{L T}=\left(\delta_{i}\right)_{Q}+\lambda\left[\left(\delta_{i}\right)_{G}+\psi\left(\delta_{i}\right)_{Q}\right]=\left(\delta_{i}\right)_{Q}+\lambda\left(\delta_{i}\right)_{Q P}
$$

where: $\left(\delta_{i}\right)_{Q},\left(\delta_{i}\right)_{G}$ and $\left(\delta_{i}\right)_{Q P}$ are the instantaneous deflection of the variable, permanent and quasi-permanent loads, respectively; $\psi$ is the coefficient for the quasipermanent value of the variable action (adopted 0.2 in this study) and $\lambda$ is the factor to take into account the long-term deflection, defined as $0.6 \xi$ for FRP RC elements following ACI 440.1R-06 (2006) recommendations. The coefficient $\xi$ takes into account creep and shrinkage, and is set equal to 2 for duration of load higher than 5 years. The instantaneous deflection due to the variable loads is defined as a portion of the quasipermanent deflection $\left(\delta_{i}\right)_{Q P}$ as:

$$
\begin{gathered}
\left(\delta_{i}\right)_{Q}=r_{Q P} \cdot\left(\delta_{i}\right)_{Q P}, \\
r_{Q P}=\frac{q_{Q}}{q_{Q P}}=\frac{q_{Q}}{q_{G}+\psi q_{Q}},
\end{gathered}
$$


where: $q_{O}$ is the variable load; $q_{G}$ is the permanent load; and $q_{Q P}$ is the quasi-permanent load. The $L / d$ ratio that limits the long-term deflection to $L / 250$ is then derived from Eqs. (37) and (38):

$$
\begin{aligned}
\frac{L}{d} & \leq \frac{1}{K_{1} K_{2} K_{3}}(d / h)^{-1} \\
\left(2 \frac{f_{c t}}{E_{c}} \beta_{1} \beta_{2}\left(\frac{M_{s}}{M_{c r}}\right)^{-1}+\frac{\varepsilon_{f}}{d / h(1-x / d)}\left(1-\beta_{1} \beta_{2}\left(\frac{M_{s}}{M_{c r}}\right)^{-2}\right)\right)^{-1} & \\
K_{3} & =250\left(r_{Q P}+\lambda\right)
\end{aligned}
$$

If other limits different from $L / 250$ want to be considered, $K_{3}$ should be changed accordingly.

\subsubsection{Slenderness limitation at a service moment ratio}

Eq. (37) needs to be evaluated at a certain service moment ratio $M_{s} / M_{c r}$. The service moment $M_{s}$, calculated under the quasi-permanent loading condition, can be typically computed as a ratio of the ultimate moment $M_{u}$, depending on the percentage of moment derived from the permanent and variable loads:

$$
\begin{gathered}
M_{u}=\gamma_{G} M_{G}+\gamma_{Q} M_{Q}, \\
M_{s}=M_{G}+\psi M_{Q},
\end{gathered}
$$

where: $M_{G}$ is the flexural moment at a cross-section obtained from the permanent loads; $M_{Q}$ is the obtained moment from the variable loads; $\gamma_{G}$ and $\gamma_{Q}$ are the partial factors for the permanent and variable loads respectively. Typical values for $\gamma_{G}$ and $\gamma_{Q}$ are 1.35 and 1.5 (Eurocode 2 2004). From Eqs (39) and (40), $M_{s} / M_{u}$ can be calculated as:

$$
M_{s} / M_{u}=\frac{r+\psi(1-r)}{\gamma_{G} r+\gamma_{Q}(1-r)},
$$

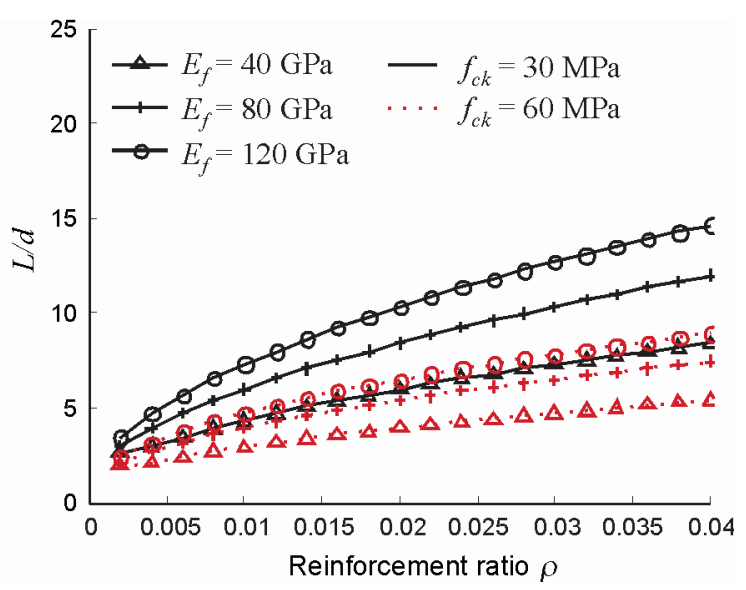

Fig. 9. $L / d$ at the service moment calculated as a ratio of the ultimate moment. Assumptions: $d / h=0.80 ; r=0.6 ; \psi=0.2$; $M_{\mathrm{s}} / M_{u}=0.48 ; \delta_{L T}=\mathrm{L} / 250 ; K_{1}=5 / 48 ; K_{2}=1$

$$
r=\frac{q_{Q}}{q_{G}+q_{Q}} .
$$

For a case where $r=0.6$ and $\psi=0.2$, the service moment due to strength requirements is $M_{s}=0.48 M_{u}$, but because serviceability requirements normally govern the design of FRP RC members, this strength moment is rarely attained, and the service moment is lower. The resultant $L / d$ for a simply supported beam subjected to a uniform load is depicted in Fig. 9.

For the range of parameters considered in this study, the $L / d$ ratio would arrive up to 15 for highly reinforced beams with low concrete strengths and high rebar modulus of elasticity. The $L / d$ ratio only depends on $\rho, f_{c k}$ and $E_{f}$. The influence of $d / h$, the bond coefficient $\beta_{1}$ and the time-loading coefficient $\beta_{2}$ result of minor importance on the $L / d$ response.

The allowable $L / d$ ratio increases as $\rho$ increases, which is the opposite behaviour of what is typically reported for steel RC (Eurocode 2 2004; Vollum 2009) for a given $M_{s} / M_{u}$. The different design criterion for FRP RC (concrete failure instead of yielding of the steel reinforcement) can explain this phenomenon. Moreover, the higher $E_{f}$, the higher allowable $L / d$ ratio, whilst low values of $f_{c k}$ allow higher $L / d$ ratios.

Eq. (37) can be applied to the conditions established by Ospina and Gross (2005) to calculate the instantaneous deflection and to compare the resultant slenderness limitations, in terms of $L / h$ ratios. The comparison is depicted in Fig. 10, taking into account the tension stiffening effect and without considering it. It is seen that the formulation presented in this work fits adequately the slenderness limitation proposed by Ospina and Gross (2005) taking into account the tension stiffening effect.

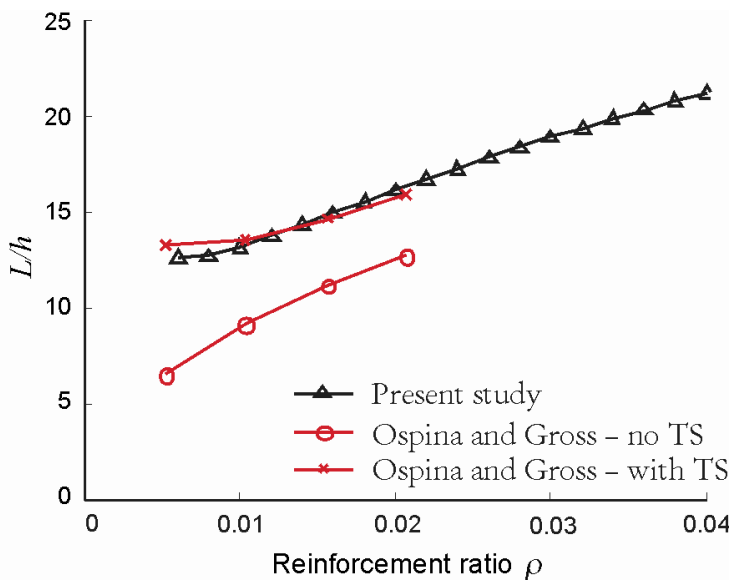

Fig. 10. $L / h$ ratios obtained by the present study compared with Ospina and Gross (2005). Assumptions: $f_{c k}=$ $34.47 \mathrm{MPa} ; E_{c}=27793 \mathrm{MPa} ; E_{f}=41369 \mathrm{MPa} ; d / h=0.90$; $M_{\mathrm{s}} / M_{u}=0.30 ; \delta_{\text {inst }}=L / 240 ; K_{1}=5 / 48 ; K_{2}=1 ; \beta_{1}=1 ; \beta_{2}=1$ 


\section{Methodology for the design of FRP RC elements under the serviceability conditions}

The present section proposes a methodology for the design of FRP RC elements under the SLS. This procedure gives as a result the optimal dimensions of a cross-section that satisfies simultaneously the SLS. The considered SLS are the stress limitation, the crack width limitation and the deflection requirements. The methodology is valid for rectangular cracked sections designed for a concrete crushing failure. First, the moment ratio at which deflections shall be evaluated is presented and second the design methodology is shown.

\subsection{Moment ratio to evaluate $L / d$}

Eq. (37), which provides the $L / d$ condition that fulfils the deflection limitation, is associated to a loading situation $\left(M_{s} / M_{c r}\right.$ or $\left.M_{s} / M_{u}\right)$. Depending on the adopted moment ratio at which to evaluate the deflection, different $L / d$ values will be obtained. The moment ratio is usually considered as a percentage of the ultimate moment. For example, Ospina and Gross (2005) consider a moment ratio $M_{s} / M_{u}$ of 0.30 and Fig. 10 shows the resultant $L / h$ ratios for a given situation.

On the other hand, for a given load condition, $L / d$ could be obtained independently from the fulfillment of

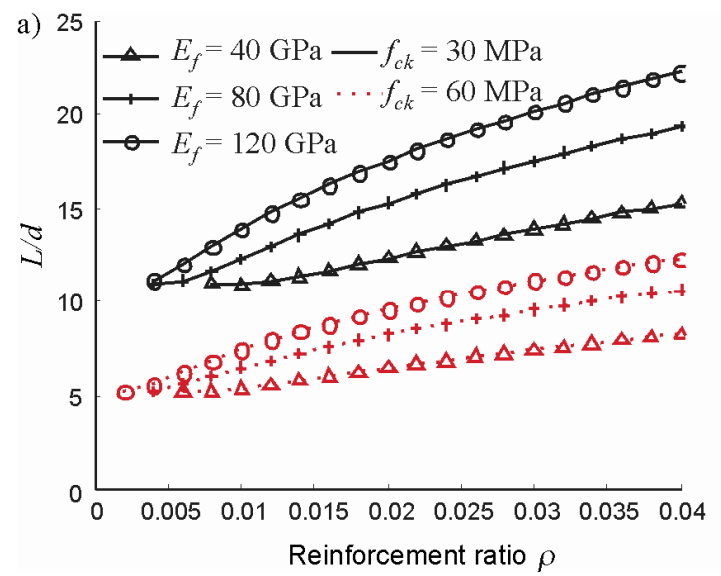

stresses and/or crack width limitations at a cross-section level using $M_{s} / M_{c r}$ according to section 2.4, and equilibrium equations. For instance, in Fig. 11 the $L / d$ ratio at the maximum $M_{s} / M_{c r}$ ratio just to fulfil the limitation of stresses is depicted for a simply-supported FRP RC beam. The beam is supposed to be subjected to uniform loading with $r=0.6$ and $\psi=0.2$. For these conditions, it is observed that the $L / d$ ratio increases with $\rho$ and $E_{f}$, whilst it decreases with $f_{c k}$, and does not depend on $\phi$ while $d / h$ seems of minor importance.

If the $L / d$ ratio is evaluated at the maximum $M_{s} / M_{c r}$ ratio to fulfil the maximum crack width requirement, Fig. 12 would be obtained instead. The $L / d$ ratio increases with $\phi$, decreases with $\rho$ and $d / h$, whilst $f_{c k}$ and $E_{f}$ are parameters of minor importance.

Using Figs 11 and 12 for the design of FRP RC elements implies that the section is designed to work under the maximum $M_{s} / M_{c r}$ ratio to satisfy the serviceability conditions of cracking and stresses at a sectional level. Nevertheless, the section may have to work at a flexural moment to fulfil also the deflection requirements (Eq. 37). Hence, the indicated $M_{s} / M_{c r}$ for cracking and stresses shall be considered a reference maximum value, and an iterative procedure can be followed to find which moment ratio gives the optimal value of the dimensions of the element.

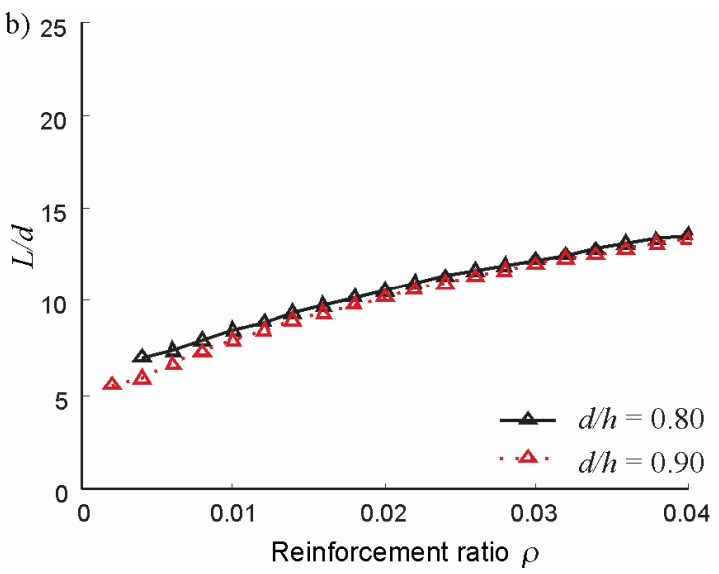

Fig. 11. $L / d$ ratio versus $\rho$. Assumptions: $\delta_{L T} / L=1 / 250 ; \sigma_{c}=0.45 f_{c k}$, high bond and long-term loading; (a) $d / h=0.80 ;$ (b) $f_{c k}=45 \mathrm{MPa}, E_{f}=80 \mathrm{GPa}$
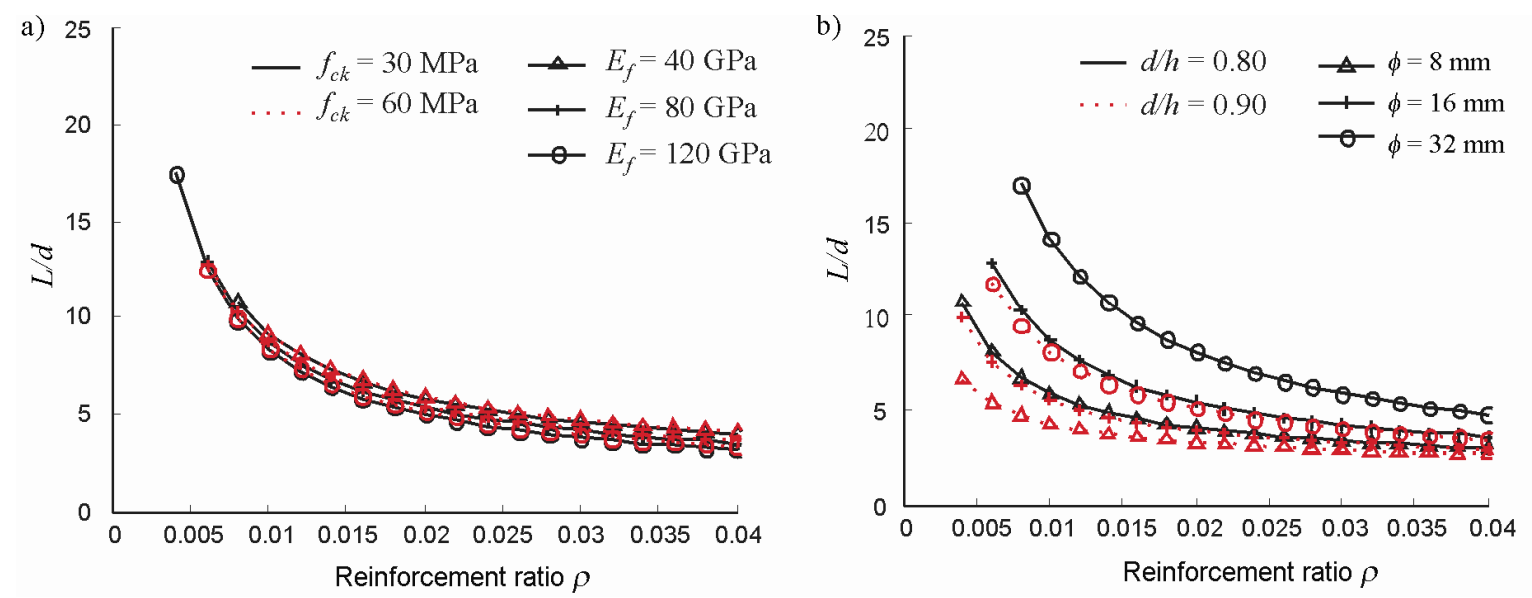

Fig. 12. $L / d$ ratio versus $\rho$. Assumptions: $\delta_{L T} / L=1 / 250, w_{k}=0.5 \mathrm{~mm}$, high bond and long-term loading; (a) $d / h=0.80, \phi=16 \mathrm{~mm}$; (b) $f_{c k}=45 \mathrm{MPa}, E_{f}=80 \mathrm{GPa}$ 


\subsection{Proposed design methodology}

The methodology aims at finding the optimal sectional height of a FRP RC element subjected to a particular loading situation and it is summarized in the flowchart of Fig. 13. It starts calculating the maximum service moment that fulfils the SLS at a cross-section level, and finds the optimal height of the element using an iterative procedure.

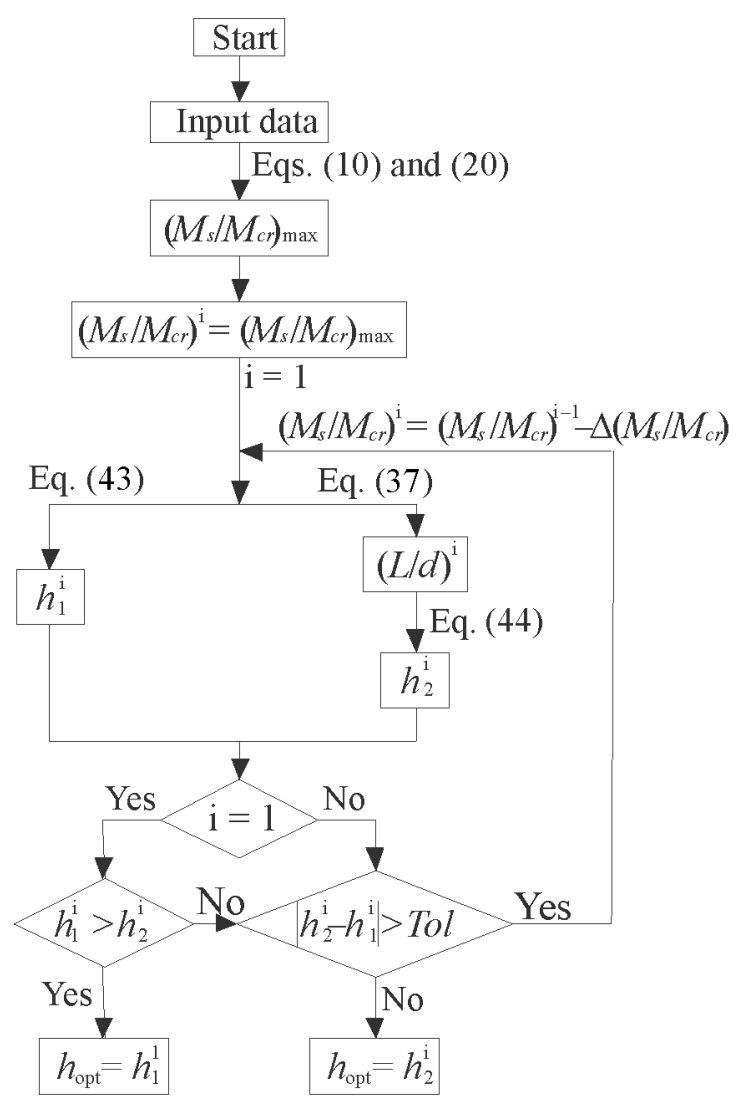

Fig. 13. Design flowchart for the dimensioning of the overall depth of a FRP RC element

The methodology is applicable to FRP RC rectangular cross-sections without compression reinforcement designed to fail by concrete crushing. The different mechanical and bond properties of the reinforcement are taken into consideration.

The problem is first defined by the input data, which are the geometric characteristics $(L, b, d / h)$; the loading conditions $\left(q_{G}, q_{Q}, \psi, K_{1}, K_{2}, \beta_{2}\right)$, the concrete and FRP mechanical properties $\left(f_{c k}, E_{c}, f_{c t}, E_{f}, \phi, \rho\right)$; the bond characteristics $\left(\beta_{1}, k_{1}\right)$; and the serviceability limitations (in this study: $\left.\sigma_{c} \leq 0.45 f_{c k}, w_{k} \leq 0.5 \mathrm{~mm}, \delta_{L T} \leq \mathrm{L} / 250\right)$.

Through Eqs (10) and (20), the maximum ratio $\left(M_{s} / M_{c r}\right)_{\max }$ is then defined as the maximum value of $M_{s} / M_{c r}$ that satisfies the stresses in materials and the crack width requirements at a cross sectional level. $\left(M_{s} / M_{c r}\right)_{\max }$ is the minimum value between the obtained by Eqs (10) and (20). If only the maximum crack width wants to be limited, $\left(M_{s} / M_{c r}\right)_{\max }$ is directly obtained from Eq. (20).
For a given loading situation, and having calculated the service moment at the section $M_{s}$, the total height of the beam $h_{1}^{1}$ is calculated from the value of $\left(M_{s} / M_{c r}\right)_{\mathrm{i}}$, which for the first iteration is $\left(M_{s} / M_{c r}\right)_{\max }$ :

$$
h_{1}^{i}=\left(\frac{6 M_{s}}{b f_{c t}}\left(\left(M_{s} / M_{c r}\right)_{i}\right)^{-1}\right)^{0.5},
$$

where $h_{1}^{1}$ corresponds to the total height of the beam that fulfils the sectional serviceability requirements (cracking and stresses). However, $h_{1}^{1}$ does not ensure the fulfilment of the deflection limitation.

In a parallel way, using Eq. (37), the $L / d$ ratio corresponding to the considered $\left(M_{s} / M_{c r}\right)_{\mathrm{i}}$ is calculated and $h_{2}^{1}$ is obtained from:

$$
h_{2}^{i}=\frac{1}{(L / d)^{i}} \frac{L}{d / h} .
$$

In the first iteration, in most of the cases, the value of $h_{2}^{1}$ results equal or higher than $h_{1}^{1}$. If $h_{2}^{1}<h_{1}^{1}$, the limitative condition is at a cross section level and $h_{\text {opt }}=h_{1}^{1}$. On the contrary, in the general case where $h_{2}^{1} \geq h_{1}^{1}$, if the difference between $h_{2}^{1}$ and $h_{1}^{1}$ is lower than a previously defined tolerance (Tol), the optimal value of the total height can be taken as $h_{2}^{1}$. If the difference between $h_{2}^{1}$ and $h_{1}^{1}$ is higher than the tolerance, initial $\left(M_{s} / M_{c r}\right)_{\max }$ should be reduced with a decrement $\Delta\left(M_{s} / M_{c r}\right)$, since the stresses and cracking limitations will be anyhow satisfied for a $M_{s} / M_{c r}$ ratio lower than $\left(M_{s} / M_{c r}\right)_{\max }$. Then, $h_{1}^{i}$ and $h_{2}^{i}$ are recalculated again.

This procedure finishes when $\left|h_{2}^{i}-h_{1}^{i}\right|<T o l$ and the optimal height of the cross section is $h_{\text {opt }}=h_{2}^{i}$. If $h_{2}^{i}-h_{1}^{i}<0$, the $M_{s} / M_{c r}$ ratio shall be increased in the next step to arrive to the optimal solution.

The presented methodology allows calculating the dimensions of FRP RC sections that fulfill the SLS in a more optimized way, since the different mechanical properties of materials, the geometric characteristics of the element, as well as the service moment caused by the applied load, can be taken into account.

Application of the methodology leads to higher values of $h$ with increasing loads. Consequently, for elements highly loaded, this methodology provides higher values of $h$ than those obtained by the slenderness limitations given in codes of practice. Conversely, for elements lightly loaded, lower values of $h$ are obtained.

Likewise, increasing values of parameters $E_{f}, d / h$ and $\rho$ result in decreasing values of $h$, as expected. The concrete strength has only relevant influence on the stress limitation condition, resulting in lower sectional dimensions as the concrete strength increases. Finally, the effect of bond coefficients is of secondary importance when compared with the other possible influencing parameters. 
This is due to the fact that, when evaluating the SLS as a whole, the SLS of cracking is generally the less restrictive one, whereas the bond properties do not have influence on the SLS of stresses in concrete, and have only influence at loads close to the cracking load for the SLS of deflections. As a result, at service loads, the effect of bond coefficients is usually not relevant.

\subsection{Example: FRP RC beam subjected to uniform loading}

The objective of this example is to illustrate the procedure previously presented. The overall depth of an FRP $\mathrm{RC}$ beam subjected to a uniform permanent load of $15 \mathrm{kN} / \mathrm{m}$ (including self-weight) and a uniform variable load of $10 \mathrm{kN} / \mathrm{m}$, over a span of $3000 \mathrm{~mm}$ (Fig. 14) wants to be determined.
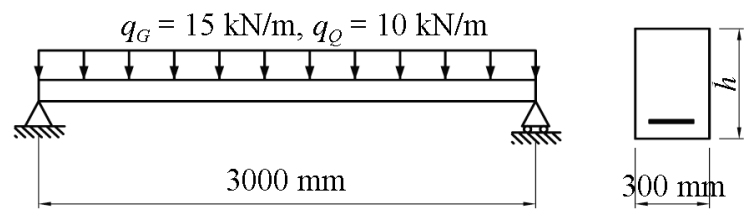

Fig. 14. Scheme of the example: simply supported beam under uniform loading

The concrete characteristic compressive strength is $45 \mathrm{MPa}$, and GFRP bars with $16 \mathrm{~mm}$ of diameter and a modulus of elasticity of $60 \mathrm{GPa}$ are used as internal reinforcement. The effective depth to overall depth ratio is 0.80 , and the section is $300 \mathrm{~mm}$ wide with a reinforcement ratio of $2 \%$. High bond is considered between concrete and reinforcement.

The coefficient for the quasi-permanent value of the variable action is considered $\psi=0.2$. The characteristic crack width is limited to $0.5 \mathrm{~mm}$, the active long-term deflection is limited to $L / 250$ and the concrete compressive stress to $0.45 f_{c k}$. In a first stage, the optimal depth of the section will be calculated to comply with the crack width limitation and the deflection limitation. The stresses in concrete limitation is subsequently taken into consideration and the optimal depth is re-calculated accordingly.

\section{Solution}

The beam is subjected to a service load, under the quasi-permanent condition of loading, of $q_{s}=q_{G}+\psi_{q Q}=$ $17 \mathrm{kN} / \mathrm{m}$. The associated bending moment is $M_{s}=$ $q_{s} L^{2} / 8=19.13 \mathrm{kNm}$. The mechanical properties of concrete $E_{c}$ and $f_{c t}$ are calculated following Eurocode 2 (2004) formulation.
First, the overall height of the beam that fulfils the maximum crack width and the deflection limitations is calculated. A tolerance $T o l$ of $5 \mathrm{~mm}$ between $h_{1}^{i}$ and $h_{2}^{i}$ will be used. Following Eq. (20) the moment ratio to comply with the maximum crack width is $M_{s} / M_{c r}=3.45$. This value leads to $h_{1}^{1}=171 \mathrm{~mm}$. On the other hand, and by using Eq. (37) with $M_{s} / M_{c r}=3.45, L / d=8.25$, giving $h_{2}^{1}=441 \mathrm{~mm}$.

Since $\left|h_{2}^{i}-h_{1}^{i}\right|>5 \mathrm{~mm}, M_{s} / M_{c r}$ is reduced and the process is again repeated. In Table 1 several iterations are shown until the optimal depth of the section is obtained.

Table 1. Iterative procedure to find the optimal depth for the given example

\begin{tabular}{ccccc}
\hline Iteration & $M_{s} / M_{c r}$ & $L / d$ & $h_{1}^{i}$ & $h_{2}^{i}$ \\
\hline 1 & 3.45 & 8.25 & 170 & 455 \\
2 & 2.5 & 11.78 & 201 & 318 \\
3 & 2 & 15.35 & 225 & 244 \\
4 & 1.9 & 16.37 & 230 & 229 \\
\hline
\end{tabular}

In iteration 4 , it is observed that $\left|h_{2}^{4}-h_{1}^{4}\right|<5 \mathrm{~mm}$, which indicates that the optimal value of the total height of the beam shall be $h_{\text {opt }}=h_{1}^{4}=230 \mathrm{~mm}$, being $\left(M_{s} / M_{c r}\right)_{\text {opt }}=1.9$ and $(L / d)_{\text {opt }}=16.37$. This situation will comply with the maximum crack width and the long-term deflection limitations.

In the following, the overall height of the beam that fulfils the three SLS (maximum crack width, deflection and stresses in concrete limitations) is calculated. If the maximum compressive stress in the concrete limitation is also taken into consideration, the initial $\left(M_{s} / M_{c r}\right)_{\max }$ is calculated as the minimum between the obtained by Eqs (10) and (20). The resulting value is $\left(M_{s} / M_{c r}\right)_{\max }=$ 2.14 , giving $L / d=14.14$, and obtaining $h_{1}^{1}=217 \mathrm{~mm}$ and $h_{2}^{1}=265 \mathrm{~mm}$. Since $\left|h_{2}^{i}-h_{1}^{i}\right|>5 \mathrm{~mm}$, the moment ratio $M_{s} / M_{c r}$ is consequently reduced and the process is again repeated. Table 1 can be used from iteration 3, and the resulting optimal depth is again $230 \mathrm{~mm}$.

This result is compared to the resultant heights obtained by ACI 440.1R-06 (2006) and other limitations present in the literature in Table 2. ACI 440.1R-06 (2006), which limits the deflection under service load $\delta_{\text {serv }}$ to $L / 240$, proposes to calculate the height of a simply supported beam as $L / 10$, whilst Ospina and Gross (2005)

Table 2. Resulting depth following the present study compared to other approaches

\begin{tabular}{llll}
\hline \multicolumn{1}{c}{ Approach } & \multicolumn{1}{c}{ Serviceability limitation } & \multicolumn{1}{c}{ Slenderness limitation } & Resultant overall depth \\
\hline ACI 440.1R-06 (2006) & $\delta_{\text {serv }} \leq L / 240$ & $L / h=10$ & $h=300 \mathrm{~mm}$ \\
Ospina and Gross (2005) & $M_{s} / M_{u}=0.30$ and $\delta_{\text {serv }} \leq L / 240$ & $L / h=12.45$ & $h=241 \mathrm{~mm}$ \\
Present study & $M_{s} / M_{u}=0.30$ and $\delta_{L T} \leq L / 250$ & $L / d=10.20(L / h=8.16)$ & $h=367 \mathrm{~mm}$ \\
Present study & $\sigma_{c} \leq 0.45 f_{c k}, w_{k} \leq 0.5 \mathrm{~mm}$, and $\delta_{L T} \leq L / 250$ & $L / d=16.37(L / h=13.10)$ & $h=230 \mathrm{~mm}$ \\
\hline
\end{tabular}


also limit the deflection under the service load $\delta_{\text {serv }}$ to $L / 240$ proposing Eq. (1). Finally, if the formulation of the present study is used and the service moment $M_{s}$ is limited to $0.30 M_{u}$, as suggested by several authors (Alsayed et al. 2000; Ospina, Gross 2005; Rafi et al. 2008), for the deflection limitation $\delta_{L T}<L / 250$, the resultant slenderness limitation would have been $L / d=10.20$, giving as a result $h=367 \mathrm{~mm}$. Hence, in this case, considering $M_{s} / M_{u}=0.30$ leads to an oversizing of the section.

For the example presented, all the slenderness limitations from other approaches provide values for the total depth of the section that result higher than the one obtained from the present methodology.

Considering of the actual loading condition and taking into account the mechanical properties of materials allows obtaining more accurate values of $h$. Moreover, it should be emphasized that the three SLS presented are simultaneously satisfied, when the other approaches only account for the deflection limit.

The presented formulation allows easily changing the limits pre-established if needed. For example, if the deflection after construction of non-structural elements $\delta_{L T}$ had been limited to $L / 500$ as stated in Eurocode 2 (2004) (i.e., considering that deflections could damage adjacent parts of the structure), the procedure would have given $L / d=14.12$ and $h=279 \mathrm{~mm}$.

Moreover, the level of loading is taken into account. Following the example, if the beam had been subjected to double the initial loading $\left(q_{G}=30 \mathrm{kN} / \mathrm{m}\right.$ and $q_{Q}=$ $20 \mathrm{kN} / \mathrm{m}$ ), the present methodology would have given $h_{\mathrm{opt}}=295 \mathrm{~mm}$, instead of $230 \mathrm{~mm}$.

\section{Conclusions}

The design of concrete structures reinforced with FRP materials is likely to be controlled by the various criteria imposed at SLS. This paper presents a discussion about the limits of the different SLS, starting from the requirements at a cross-section level to end up with the deflection limitation. Based on Eurocode 2 (2004) formulation, a methodology to fulfill the serviceability requirements for the design of the overall depth of a FRP RC element is presented.

The study on stresses in materials shows that limiting the compressive stress in the concrete to $0.45 f_{c k}$ under the quasi-permanent combination of loads gives somehow restrictive values of the maximum service moment to be attained at the section. However, this limitation shall be evaluated for each specific situation, since it refers mainly to assuming linear creep and to avoiding longitudinal cracks that may lead to a reduction in the durability.

The limitation of the tensile stress in the FRP reinforcement, which refers to avoiding the creep rupture, highly depends on the rebar properties, the environmental conditions and the loading period. Although further studies would be needed to arrive to a more generalized conclusion, for the range of values studied in this work, limiting the stress in the FRP bar generally leads to less restrictive situations than limiting the concrete stress.
Limiting the maximum crack width to a characteristic value of $0.5 \mathrm{~mm}$ leads to service moments generally higher than those obtained for the SLS of concrete stress. Only in few cases with low reinforcement ratios, the crack width criterion may be governing the SLS at a cross-section level. The maximum allowable tensile strain is compared to the values established in the literature, finding that in most cases limiting $\varepsilon_{f}$ to $2000 \mu \varepsilon$, can result too restrictive, especially in those cases where high bond is reported or for reinforcement ratios higher than $2 \%$.

The service moment that fulfils the serviceability requirements at cross-section level ranges between 0.20 and 0.38 times the ultimate moment for sections dimensioned to fail in concrete crushing. This range of values results in good agreement with the ones stated by Bischoff (2005) and Ospina and Gross (2005).

A formulation to calculate the $L / d$ ratio that fulfils the deflection limitation for an FRP RC element is provided. This equation allows considering the different properties of materials as well as the geometric and loading conditions of the element. Results show that the $L / d$ ratio only depends on $\rho, f_{c k}$ and $E_{f}$. Moreover, the $L / d$ ratio increases with $\rho$, which is the opposite behavior of what is typically reported for steel RC.

An iterative methodology to calculate the height of a FRP RC beam that can simultaneously satisfy all of the considered SLS is presented. This procedure allows optimizing the overall depth of the element with respect to those usually adopted in practice, since it accounts for the specific mechanical properties of materials and the geometric and loading conditions of the element. This methodology provides higher values of $h$ as the applied load increases, as expected. High values of $E_{f}, d / h$ and $\rho$ result in lower values of $h$, whilst $f_{c k}$ has only relevant influence on the limitation of the compressive stress, leading to lower values of $h$ as the $f_{c k}$ increases. The effect of bond factors results secondary, since it affects to the maximum crack width limitation, which is not usually restrictive.

\section{Acknowledgements}

The authors acknowledge the support provided by the Spanish Government (Ministerio de Ciencia e Innovación), Project ref. BIA2010-20234-C03-02.

\section{References}

ACI 440.2R-08 Guide for the design and construction of externally bonded FRP systems for strengthening concrete structures. American Concrete Institute (ACI), Farmington Hills, Michigan, USA, 2008. 41 p.

ACI 440.1R-06 Guide for the design and construction of concrete reinforced with FRP bars. American Concrete Institute (ACI), Farmington Hills, Michigan, USA, 2006. $45 \mathrm{p}$.

Alsayed, S. H. 1998. Flexural behaviour of concrete beams reinforced with GFRP bars, Cement and Concrete Composites 20(1): 1-11. http://dx.doi.org/10.1016/S0958-9465(97)00061-9

Alsayed, S. H.; Al-Salloum, Y. A.; Almusallam, T. H. 2000. Performance of glass fiber reinforced plastic bars as a 
reinforcing material for concrete structures, Composites Part B: Engineering 31(6-7): 555-567.

http://dx.doi.org/10.1016/S1359-8368(99)00049-9

Baena, M.; Turon, A.; Torres, L1.; Miàs, C. 2011. Experimental study and code predictions of fibre reinforced polymer reinforced concrete (FRP RC) tensile members, Composite Structures 93(10): 2511-2520.

http://dx.doi.org/10.1016/j.compstruct.2011.04.012

Barris, C.; Torres, L.; Baena, M.; Pilakoutas, K.; Guadagnini, M. 2012. Serviceability limit state of FRP RC beams, Advances in Structural Engineering 15(4): 653-664. http://dx.doi.org/10.1260/1369-4332.15.4.653

Bischoff, P. H. 2005. Reevaluation of deflection prediction for concrete beams reinforced with steel and fiber reinforced polymer bars, Journal of Structural Engineering 131(5): 752-762. http://dx.doi.org/10.1061/(ASCE)0733-9445 (2005)131:5(752)

Bischoff, P. H. 2007. Rational model for calculating deflection of reinforced concrete beams and slabs, Canadian Journal of Civil Engineering 34(8): 992-1002.

http://dx.doi.org/10.1139/107-020

CNR-DT-203 Guide for the Design and Construction of Concrete Structures Reinforced with Fiber-Reinforced Polymer Bars. Advisory Committee on Technical Recommendations for Construction, 2006. 39 p.

El-Salakawy, E. F.; Benmokrane, B. 2004. Serviceability of concrete bridge deck slabs reinforced with FRP composite bars, ACI Structural Journal 101(5): 727-736.

EN 1992-1-1:2004 Eurocode 2: Design of Concrete Structures-Part I: General Rules and Rules for Buildings. CEN, Brussels, 2004.

EN 1992-1-1:2002 Eurocode 2: Design of Concrete Structures - Part I: General Rules and Rules for Buildings. CEN, Brussels, 2002.

Ghali, A.; Hall, T.; Bobey, W. 2001. Minimum thickness of concrete members reinforced with fibre reinforced polymer bars, Canadian Journal of Civil Engineering 28(4): 583-592. http://dx.doi.org/10.1139/cjce-28-4-583

Gribniak, V.; Kaklauskas, G.; Čygas, D.; Bačinskas, D.; Kupliauskas, R.; Sokolov, A. 2010. Investigation of concrete cracking effect in deck slab of continuous bridges, The Baltic Journal of Road and Bridge Engineering 5(2): 8388. http://dx.doi.org/10.3846/bjrbe.2010.12

Hollaway, L. C. 2010. A review of the present and future utilisation of FRP composites in the civil infrastructure with reference to their important in-service properties, Construction and Building Materials 24(12): 2419-2445. http://dx.doi.org/10.1016/j.conbuildmat.2010.04.062

Huang, J.; Aboutaha, R. 2010. Environmental reduction factors for GFRP bars usd as concrete reinforcement: New scientific approach, Journal of Compostes for Construction ASCE 14(5): 479-486. http://dx.doi.org/10.1061/(ASCE)CC.1943-5614.0000122

ISIS Canada. 2001. Reinforcing concrete structures with fibre reinforced polymers - Design manual No. 3. ISIS Canada Corporation, University of Manitoba, Manitoba, Canada. $158 \mathrm{p}$.

Kara, I. F.; Ashour, A. F. 2012. Flexural performance of FRP reinforced concrete beams, Composite Structures 94(5): 1616-1625.

http://dx.doi.org/10.1016/j.compstruct.2011.12.012
Kaklauskas, G.; Gribniak, V.; Jakubovskis, R.; Gudonis, E.; Salys, D.; Kupliauskas, R. 2012. Serviceability analysis of flexural reinforced concrete members, Journal of Civil Engineering and Management 18(1): 24-29. http://dx.doi.org/10.3846/13923730.2011.643553

Matthys, S.; Taerwe, L. 2000. Concrete slabs reinforced with FRP grids. I: One-way bending, Journal of Composites for Construction ASCE 4(3): 145-153. http://dx.doi.org/10.1061/(ASCE)1090-0268(2000)4: $3(145)$

Nanni, A. 2003. North American design guidelines for concrete reinforcement and strengthening using FRP: principles, applications and unresolved issues, Construction and Building Materials 17(6-7): 439-446. http://dx.doi.org/10.1016/S0950-0618(03)00042-4

Newhook, J.; Ghali, A.; Tadros, G. 2002. Concrete flexural members reinforced with fiber reinforced polymer: design for cracking and deformability, Canadian Journal of Civil Engineering 29(1): 125-134. http://dx.doi.org/10.1139/101-085

Ospina, C. E.; Gross, S. P. 2005. Rationale for the ACI 440.1R06 indirect deflection control design provisions, in Proc. of the 7th International Symposium on Fibre-Reinforced Polymer Reinforcement for Concrete Structures, American Concrete Institute (ACI), 2005, 651-667.

Pecce, M.; Manfredi, G.; Cosenza, E. 2001. A probabilistic assessment of deflections in FRP RC beams, in Proc. of the 5th International Symposium on Fibre-Reinforced Polymer Reinforcement for Concrete Structures, American Concrete Institute (ACI), 2001, Vol. 2, 887896.

Pecce, M.; Manfredi, G.; Cosenza, E. 2000. Experimental response and code models of GFRP RC beams in bending, Journal of Composites for Construction ASCE 4(4): 182190. http://dx.doi.org/10.1061/(ASCE)1090-0268(2000)4: 4(182)

Rafi, M. M.; Nadjai, A. 2009. Evaluation of ACI 440 deflection model for fiber-reinforced polymer reinforced concrete beams and suggested modification, ACI Structural Journal 106(6): 762-771.

Rafi, M. M.; Nadjai, A.; Ali, F.; Talamona, D. 2008. Aspects of behaviour of CFRP reinforced concrete beams in bending, Construction and Building Materials 22(3): 277-285. http://dx.doi.org/10.1016/j.conbuildmat.2006.08.014

Saikia, B.; Kumar, P.; Thomas, J.; Nanjunda Rao, K. S.; Ramaswamy, A. 2007. Strength and serviceability performance of beams reinforced with GFRP bars in flexure, Construction and Building Materials 21(8): 1709-1719. http://dx.doi.org/10.1016/j.conbuildmat.2006.05.021

Soric, Z.; Kisicek, T; Galic, J. 2010. Deflections of concrete beams reinforced with FRP bars, Materials and Structures 43, Supplement 1: 73-90. http://dx.doi.org/10.1617/s11527-010-9600-1

Veysey, S.; Bischoff, P. H. 2011. Designing FRP reinforced concrete for deflection control, ACI Special Publication 275: 1-24. http://dx.doi.org/10.1061/(ASCE)CC.19435614.0000195

Vollum, R. L. 2009. Comparison of deflection calculations and span-to-depth ratios in BS 8110 and Eurocode 2, Magazine of Concrete Research 61(6): 465-476. http://dx.doi.org/10.1680/macr.2009.61.6.465 
Cristina BARRIS. Lecturer in the Dept. of Mechanical Engineering and Industrial Construction at the University of Girona, and member of the research group on Advanced Materials and Analysis for Structural Design. She works on analytical and experimental analysis of concrete structures. Her research interests include the flexural performance of concrete elements reinforced with FRP materials, specially their serviceability behaviour.

Lluís TORRES. Professor of Structural Engineering and member of the research group on Advanced Materials and Analysis for Structural Design in the Polytechnic School at the University of Girona, Spain. He is member of the fib Task Groups 9.3 "FRP reinforcement for concrete structures" and 4.1 "Serviceability models". His research interests include the experimental and numerical analysis of reinforced concrete structural elements.

Cristina MIÀS. PhD student in the Dept. of Mechanical Engineering and Industrial Construction at the University of Girona, and member of the research group on Advanced Materials and Analysis for Structural Design. Her research interests include the experimental and numerical analysis of concrete elements reinforced with FRP materials.

Irene VILANOVA. PhD student in the Dept. of Mechanical Engineering and Industrial Construction at the University of Girona, and member of the research group on Advanced Materials and Analysis for Structural Design. Her research interests include the experimental and numerical analysis of concrete elements reinforced with FRP materials. 